\title{
Veni Sancte Spiritus: um moteto de José Maurício Nunes Garcia
}

\author{
Marcos da Cunha Lopes Virmond (Univ. Sagrado Coração, Bauru, SP) \\ mvirmond@ilsl.br
}

\author{
Lenita Waldige Mendes Nogueira (UNICAMP, Campinas, SP) \\ Iwmn@iar.unicamp.br
}

\begin{abstract}
Resumo: A produção musical no gênero sacro teve importantes representantes no periodo do Brasil Colônia e Imperial, entre os quais se destaca o Padre José Maurício Nunes Garcia, responsável pela música da Sé Imperial do Rio de Janeiro antes e após a chegada da família real em 1808. Sua vasta produção resistiu ao tempo através de manuscritos autógrafos ou não, os quais têm sido alvo de intensos estudos, com destaque para as pesquisas pioneiras de Cleofe Person de Mattos. Mesmo assim, atualmente, apenas parte de sua obra encontra-se restaurada do ponto de vista musicológico com vistas à perfomance. Desta forma, este estudo visa comentar a transcrição musicológica de um moteto de exemplar fatura, intitulado Veni Sancte Spiritus, para pequena orquestra de cordas, duas flautas e coro a quatro vozes.
\end{abstract}

Palavras-chave: José Maurício Nunes Garcia; música colonial brasileira, musicologia histórica, moteto Veni Sancte Spiritus.

\section{Veni Sancte Spiritus: a motet by José Mauricio Nunes Garcia}

Abstract: Sacred musical production had important representatives in the period of colonial and imperial Brazil, among which stands out Father José Maurício Nunes Garcia, in charge of music at the Royal Chapel in Rio de Janeiro before and after the arrival of the royal family in 1808. His vast output resisted time through autograph manuscripts or copies, which have been the target of intense study, especially the pioneering research of Cleofe Person de Mattos. Yet, currently, only part of his work is restored from the musicological point of view in what regards performance. Thus, this study aims to comment on the musicological transcription of a motet entitled Veni Sancte Spiritus, for small orchestra of strings, two flutes and a four-voice choir.

Keywords: José Maurício Nunes Garcia; Brazilian colonial music; historical musicology; motet Veni Sancte Spiritus.

\section{1- Introdução}

José Maurício Nunes Garcia (1767-1830) viveu no Rio de Janeiro e era um mulato claro de mãe descendente de escravos, fato com repercussões em sua futura carreira. Teve uma esmerada educação, dentro das limitações sociais da família, e estudou música com Salvador José, um tradicional professor no Rio de Janeiro de então. Foi ordenado sacerdote aos 25 anos de idade, mais provavelmente por necessidade de impulsionar suas pretensões, uma vez que essa condição poderia Ihe favorecer conhecimentos e trânsito nos ambientes formais da colônia.

Era de invulgar cultura para a época, tendo feito um curso de retórica em 1802 e, de fato, foi muito afamado como orador sacro, ao lado de suas atuações como músico. Obteve a importante condição de mestre-capela da Catedral e Sé do Rio de Janeiro, situação que melhor the coube com a chegada da Família Real em 1808. D. João VI muito prestigiou o padre e dotou a então capela real com recursos consideráveis em termos de interpretação musical. Alguns viajantes europeus comentavam que a orquestra da Sé Imperial era comparável às boas orquestras do VeIho Continente.

Entretanto, esta situação mudou em 1811 com a chegada do renomado compositor lisboeta Marcos Portugal. A corte, fortemente lusófila, preferiu prestigia-lo em detrimento de José Mauricio. Este ainda soube articular-se habilmente para manter algum prestigio, principalmente modificando sua estética composicional, adotando os maneirismos da ópera napolitana que tanto agradavam a corte portuguesa, modo este fielmente adotado e divulgado por Marcos Portugal no Rio. Mas o declínio era ine- 
vitável e até o fim de sua vida não logrou maiores glórias. Foi professor de música de D. Pedro I, mas, mesmo assim, após o retorno de D. João VI a Portugal, esta ligação não Ihe foi favorável, uma vez que os recursos existentes e a própria disponibilidade do novo imperador não eram prioritariamente dedicados às atividades musicais.

A obra de José Maurício é extensa, mas basicamente se restringe ao gênero sacro. Suas incursões na área profana são poucas, ainda que significativas como o caso da Abertura Zemira (1803). De fato, sua produção religiosa é suficiente para enaltecer-lhe o nome. Teve sempre uma escrita limpida e despojada, mas de melodismo cativante. Conhecia bem as obras de Haydn e Mozart, dois compositores que se percebe terem influenciado sobremaneira sua escrita. Mas, nem por isto, sua obra deixa de ter personalidade própria. Talvez pela imposição acima referida de Marcos Portugal, abandona, em seu período final, este frescor e simplicidade efetiva, para uma ornamentação mais pesada que nada lhe acrescentou em grandeza e originalidade. Neste sentido, KIEFER (1976, p.58), com sua objetividade e fino escrutínio refere:

\footnotetext{
Estilisticamente, José Mauricio é um reflexo da Europa. 0 que há nele de pessoal manifesta-se em termos europeus e não através de uma contribuição que revelasse um modo de ser brasileiro. Globalmente. Uma audição mais refinada, no entanto, poderá descobrir, aqui e acolá, sombras do clima modinheiro, quase um prenúncio da aurora do sentimento nativo na musica brasileira erudita.
}

Entretanto, salienta-se uma citação, ainda que breve, feita por PAZ (1977, p.391) que afirma apresentar este compositor, juntamente com Damião Barbosa de Araújo e José Rebouças, uma realização técnica muito superior àquelas que outras regiões da América Latina podiam oferecer na época.

0 processo de recuperação da obra mauriciana teve seu maior esforço na figura de Cleofe Person de Mattos. Além do Catálogo Temático, obra de inestimável valor, sob sua coordenação, algumas obras foram restauradas e editadas pelo Ministério da Educação e Cultura, através da FUNARTE. Mais recentemente, a obra mauriciana tem encontrado a merecida atenção, não só na produção de edições modernas (FIGUEIREDO, 2001, 2005) como na execução pública e gravação sonora. Dentro do crescente intento de divulgação do seu legado, o objetivo deste trabalho é apresentar e discutir a transcrição de um pequeno moteto desse compositor.

\section{2- Fontes e Métodos}

José Maurício atuou no Rio de Janeiro, mas suas obras circularam de forma geograficamente ampla no território nacional, através dos copistas. Em parte isto se deve à tradição da música de igreja, que teve forte apelo nos séculos XVIII e XIX no Brasil. Assim é que, entre outros locais, como cidades de São Paulo e Minas Gerais, Rio Pardo no Rio Grande do Sul foi sede de um acervo mauriciano. Esta cidade teve importância nos séculos XVIII e XIX por suas características estratégicas. Ela era o ponto mais setentrional para o avanço fluvial dos portugueses visando a consolidação e controle dos limites da colônia e, posteriormente, do Império, atuando como centro militar e comercial. Como bem explica MACEDO (1984, p.20):

Por tais razões Rio Prado assumia importância quase tão grande como a da capital. Era o centro administrativo, político e econômico da maior parte do Continente de São Pedro. Sua população durante algum tempo, teria sido superior à de Porto Alegre...(MACED0, 1984, p.20).

0 conjunto arquitetônico, até hoje preservado, atesta essa relevância, assim como os relatos e o acervo referentes à intensa vida musical da cidade (LAYTANO, 1952, p.200-207).

A Matriz da cidade possuía um acervo musical importante, incluindo várias obras de José Maurício. Entre os manuscritos não autógrafos encontrava-se um delicado moteto intitulado "Gradual para a Solenidade do Espírito Santo - Veni Sancte Spiritus - a 4 vozes" o qual, até o momento, não foi alvo de nenhum tratamento musicológico. Este moteto foi encontrado por Cleofe Person de Mattos no acervo do Coral Santa Cecília de Rio Pardo e incluído em seu catálogo temático das obras de José Maurício sob número CPM 156 (MATTOS, 1970, p.225-226). A obra não apresenta data e a fonte primária é o conjunto de partes cavadas proveniente de Rio Pardo, em cópias assinadas por um certo Lima. Há, também, um conjunto de cópias modernas deixadas naquela cidade, uma vez que parte do acervo original foi doado à Academia Brasileira de Música. Desta forma, não se conhece o manuscrito autógrafo desta obra.

Para a transcrição utilizaram-se como elementos textuais as cópias atuais deixadas em Rio Pardo e as cópias das partes cavadas do moteto realizadas por Lima. Essas últimas consistem em um conjunto de dez folhas de papel medindo $21 \mathrm{~cm} \times 31 \mathrm{~cm}$, com as partes instrumentais e vocais separadas, a saber: flauta $1^{\text {a }}$, flauta $2^{a}$, tiple, altus, tenor, basso, violino $1^{\circ}$, violino $2^{\circ}$ e basso. Na folha de rosto, pode ser lido:

$$
\begin{gathered}
\text { Gradual } \\
\text { Pa. a Solemnidade do Esp. }{ }^{\text {to }} \text {. S. }{ }^{\text {to }} \\
\text { Veni Sancte Spiritus a } 4 \text { vozes } \\
\text { Pelo Pd. José Maurício } \\
\text { Lima }
\end{gathered}
$$

\section{3- 0 Moteto}

0 texto para este moteto é de origem medieval e corresponde a uma das poucas seqüências para o Pentecoste que permaneceram no Missale Romanum após o Concilio de Trento no século XVI, sendo cantada até hoje. Trata-se de um gradual, isto é, o segundo item do próprio da missa, que tem comumente conteúdo responsorial. Na leitura do Padre José Maurício, isto não ocorre, tratando o texto do gradual dentro da forma tradicional do moteto. 0 texto (mostrado abaixo no original e traduzido) fala das virtudes do Santo Espírito e invoca sua vinda: 


\author{
Veni Sancte Spiritus \\ et emite celitus \\ lucis tue radium. \\ Veni Pater pauperum. \\ Veni dator munerum. \\ Veni lumen cordium \\ consolator optime. \\ Dulcis hospes anime \\ dulce refrigerium. \\ Da virtutis meritum, \\ da salutis exitum. \\ Da perene gaudium. \\ Amen.
}

A obra está escrita para coro misto a quatro vozes com acompanhamento de dois violinos, baixo e duas flautas. A textura é claramente homofônica no que se refere ao tratamento do coro e em contraponto florido para o acompanhamento orquestral. Este tem a função de suportar a harmonia, embelezar e emprestar movimento à evolução quase estática da parte homofônica do coro.

A obra está na tonalidade de Mi menor, com fórmula de compasso $3 / 4$ e se desenvolve ao longo de cinqüenta e seis compassos. 0 conteúdo está distribuído em cinco seções que apresentam características individuais. A curta seção introdutória é de exposição e afirmação tonal, distribuída em quatro frases de dois compassos cada. Na segunda seção, c.9-20, o coro é introduzido e a orquestra assume seu papel de acompanhamento e ornamentação. As flautas têm intervenção de apoio às vozes corais, particularmente ao soprano. Em alguns momentos, a primeira flauta acrescenta alguns elemen-

\author{
Vinde, Espírito Santo \\ enviai dos céus \\ um raio de luz! \\ Vinde, Pai dos pobres. \\ Vinde, doador de dons. \\ Vinde, luz dos corações, \\ consolo que acalma, \\ Doce hóspede da alma \\ doce alivio. \\ Dai o mérito da virtude \\ Daí o porto da salvação \\ Daí o eterno gozo. \\ Amém.
}

tos da tríade que está sendo exposta ou pratica notas de passagem para o encadeamento de um acorde para outro. Este segmento é composto de três frases de quatro compassos cada, perfazendo um conjunto de 12 compassos. A terceira seção, c.21-30, é a seção central iniciando na relativa maior - Sol maior. São duas frases com cinco compassos cada. A primeira, na relativa maior, novamente terminando na cadência $I^{6 / 4}-V^{7}-I$, seguida pela segunda frase já na tonalidade principal, Mi menor. A característica desta seção, e daí entenderse como a seção central, é que ela conclui com uma cadência evitada (interrompida) V-VI, levando à quarta seção (Ex.1). Esta seção, c.31-44, similar à anterior, conclui novamente com mais uma cadência evitada. Estes são pontos climáticos importantes da obra e merecem atenção na parte interpretativa, uma vez que os documentos autógrafos apenas raramente apresentam indicação de dinâmica e de articulação. Após esta cadência, entra-se na última seção da obra.

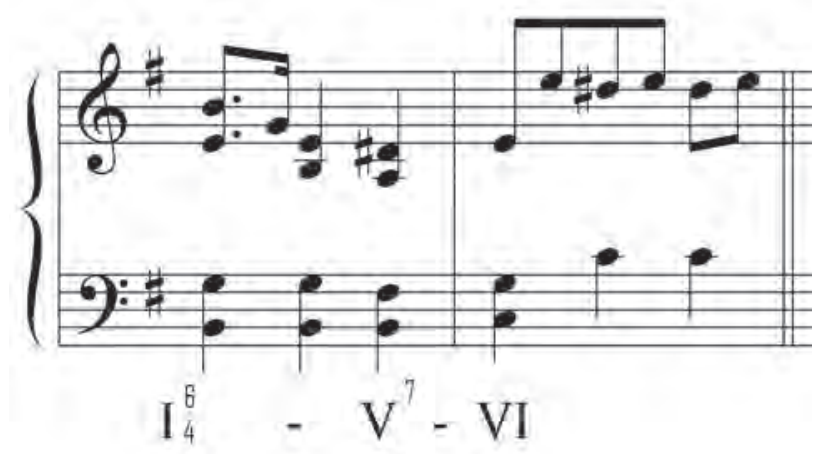

Ex.1 - Final da seção central (c.29-30) mostrando a cadência interrompida em Veni Sante Spiritus de J.M. Nunes Garcia. 


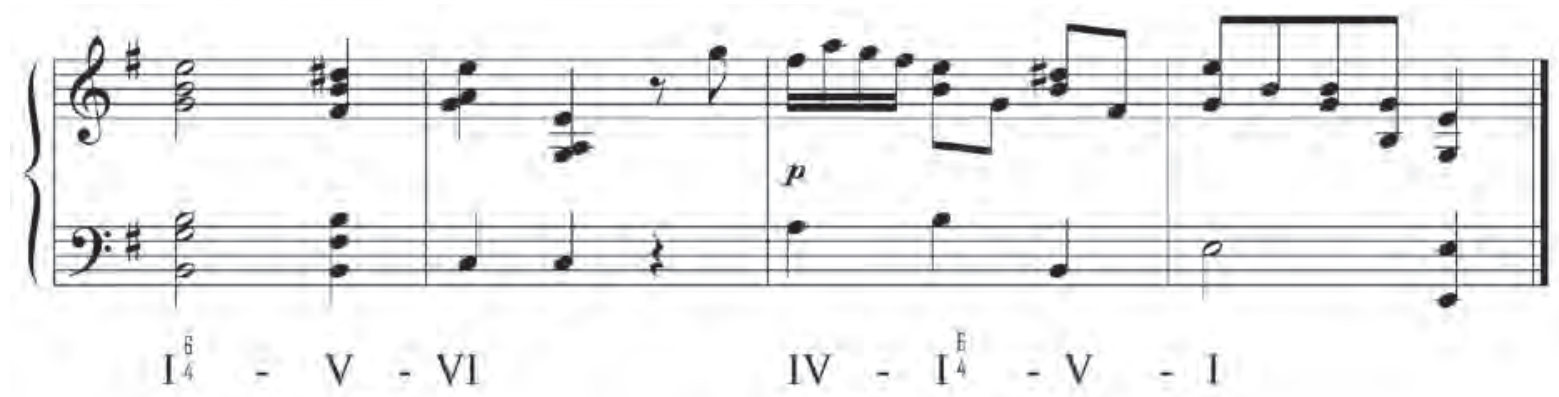

Ex.2 - Cadências da seção final (c.53-56) em Veni Sante Spiritus de J.M. Nunes Garcia.

\begin{tabular}{|c|c|c|c|}
\hline seção & compassos & caracteristica & tonalidade \\
\hline 1 & $1-8$ & introdução & Mi menor \\
\hline 2 & $9-20$ & apresentação coral & Mi menor \\
\hline 3 & $21-30$ & central & Sol maior/Mi menor \\
\hline 4 & $31-44$ & climática & Dó maior/Mi menor \\
\hline 5 & $45-56$ & final & Mi menor \\
\hline
\end{tabular}

Ex.3 - Quadro esquemático das seções de Veni Sante Spiritus de J.M. Nunes Garcia.

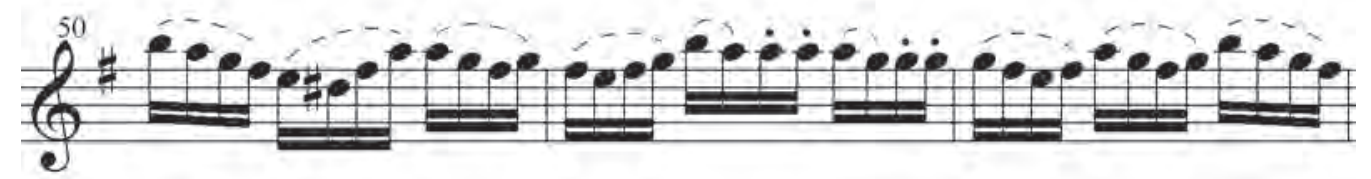

Ex.4 - Sugestão de articulação em seqüência de semicolcheias do $1^{\circ}$ violino (c.50) em Veni Sante Spiritus de J.M. Nunes Garcia.

A quinta e última seção, c.45-56, apresenta nos violinos um desenho constante em semicolcheias que empresta a esta parte um caráter de maior movimento e, sem dúvidas, de melhor elaboração. Ao final, José Maurício utiliza novamente uma cadência interrompida para suspender a frase antes de apresentar uma curta finalização de dois compassos de franco caráter de reafirmação tonal e conclusão retórica (Ex.2). Um sumário das seções pode ser visto na Exemplo 3.

Os documentos textuais apresentam pouca informação quanto à dinâmica e nenhuma para articulação. Assim, dentro do contexto de transcrição musicológica, optouse por incluir na reconstrução apenas as indicações que se achavam claramente identificadas nas partes cavadas. Neste sentido, a parte do baixo instrumental é o documento mais completo. Abreviaturas de época, no caso pmo, foram modernizadas para pp. 0 contraste entre for- te e piano dentro do mesmo compasso, que acontece a partir do c.13, pode, em um primeiro momento, parecer pouco usual. Entretanto, devemos lembrar a influência de Haydn sobre o Padre José Maurício, o que justificaria o uso dessa indicação.

Quanto às correções, a única realizada foi no c.21 da parte de primeiro violino, um Ré ${ }_{6}$ substituindo um $\mathrm{Mi}_{6}$ na cópia, seguindo a lógica harmônica e a frase do coro. Inconsistências de duração de notas também foram preservadas conforme o original, caso das duas flautas que, ora uma ora outra, apresentam valor de mínima pontuada e mínima com pausa (c.54 e c.56).

Com exceção do c.5 (primeiro violino) não há indicações de articulação nos documentos. Optou-se, novamente, por não incluir sugestões de articulação. No que se refere às arcadas, alguns exemplos podem servir de orientação ao intérprete (Ex.4 e Ex.5). 


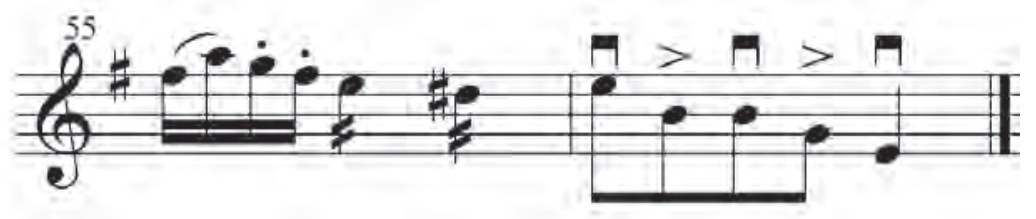

Ex.5 - Sugestão de articulação na frase final do $1^{\circ}$ violino (c.55) em Veni Sante Spiritus de J.M. Nunes Garcia: ligadura seguida de staccato nas semicolcheias descendentes e acento nas colcheias finalizadoras.

\section{4- Considerações finais}

0 Padre José Maurício Nunes Garcia apresenta uma importante literatura de música sacra. Seu estilo é fortemente influenciado pelos clássicos, particularmente Haydn, mas suas obras revelam uma singeleza própria e uma dramaticidade que lhe empresta envergadura. Se existem extensas lacunas na construção da história da música brasileira, causadas principalmente pelas características do processo de formação da nação, José Maurício surge, na virada do século XVIII como um compositor nacional que muito con- tribuiu para a identidade da cultura musical do país. Não se trata, certamente, de nacionalismo em música, que viria mais tardiamente com Villa Lobos, mas no estabelecimento de uma produção distintamente autóctone ainda que impregnada pela estética da metrópole.

0 moteto Veni Sancte Spiritus CPM 156 serve como exemplo claro do que acima foi dito - uma obra despretensiosa, mas cristalina em sua construção e com vívida dramaticidade emanando de sua estrutura simples e despojada.

\section{Referências}

FIGUEIREDO, Carlos Alberto. A Crítica Genética e a Obra de José Maurício Nunes Garcia. Cadernos do Colóquio. Rio de Janeiro, p.34-40, 2000. p.34-40

FIGUEIRED0, Carlos Alberto. As edições de obras sacras de José Maurício Nunes Garcia. Anais do XV Congresso da ANPPOM, p.758-765, 2005

KIEFER, Bruno. História da Música Brasileira - dos primórdios ao início do século XX. Porto Alegre: Editora Movimento, 1976.

LAYTANO Dante de. Vida religiosa de cidade do interior - Crônica das Irmandades Tradicionais do Rio Pardo. Revista do Museu Júlio de Castilhos e Arquivo Histórico do Rio Grande do Sul. Ano I. n², p.202-207, 1952.

LIMA, Rossini Tavares de. Vida e época de José Maurício. Rio de Janeiro: Livraria Elo, 1941, 113p.

MACEDO, Francisco Riopardense de. Arquitetura no Brasil de Araújo Porto Alegre. Porto Alegre: Ed. da Universidade, 1984.

MATTOS, Cleofe Person de. Catálogo Temático - José Maurício Nunes Garcia. Rio de Janeiro: Conselho Federal de Cultura - MEC, 1970, p.225-226.

NEVES, José Maria. Presença de Francisco Curt Lange. Anais - I Simpósio Latino Americano de Musicologia, p.15-18. Fundação Cultural de Curitiba, 1998.

PAZ, Juan Carlos. Introdução à Música de Nosso Tempo. São Paulo: Livraria Duas Cidades, 1977, p.391.

Marcos da Cunha Lopes Virmond é professor do Departamento de Música da Universidade Sagrado Coração em Bauru, SP e regente titular da Orquestra Sinfônica Municipal de Botucatu.

Lenita Waldige Mendes Nogueira é professora de História da Música e do Programa de Pós-Graduação em Música do Instituto de Artes da UNICAMP. 